\title{
ANALISA SISTEM PENGENDALIAN BAHAN BAKAR MINYAK HIGH SPEED DIESEL DI PLTD KLADEMAK SORONG, PAPUA BARAT
}

\author{
Irman Amri ${ }^{* *}$, Masniar ${ }^{2}$, Joni Budiman Efendi Laos ${ }^{3}$ \\ ${ }^{1,2}$ Dosen Program Studi Teknik Industri Universitas Muhammadiyah Sorong \\ Jln. Pendidikan No 27 Kota Sorong, Papua Barat \\ ${ }^{3}$ PT. PLN Persero Cabang Sorong \\ Jln. Achmad Yani Kota Sorong \\ *Email: irmanamri_srg@yahoo.com
}

\begin{abstract}
Abstrak
PLTD Klademak Sorong merupakan salah satu bagian dari sistem interkoneksi pembangkit energi listrik yang ada di kota Sorong dan sekitarnya. Kekurangan persediaan BBM HSD sangat dihindari, karena akan menimbulkan biaya kegagalan proses yang cukup besar. Namun selama tahun 2011 sampai dengan 2015 kekurangan persediaan bahan baku masih saja terjadi, hal ini menunjukkan bahwa sistem pengendalian persediaan yang dilakukan oleh perusahaan belum optimal. Penelitian ini ingin mengetahui pengendalian persediaan yang optimal menurut metode Material Resource Planning, kemudian hasilnya dibandingkan dengan metode perusahaan dari segi total biaya persediaan yang terjadi. Selain itu penelitian ini juga akan melakukan peramalan permintaan BBM HSD untuk tahun 2017 dan dari data peramalan permintaan tersebut dicari jumlah pembelian yang dapat mengoptimalkan biaya langsung penyimpanan dan biaya kebalikannya yaitu biaya pemesanan BBM HSD.Hasil penelitian menunjukkan persentase penghematan biaya persediaan yang dihasilkan melalui penerapan MRP adalah sebesar 3,2 \% pada teknik LFL, dan 31,5\% pada teknik EOQ, serta 51,6\% pada teknik PPB. Ini menunjukkan dari ketiga alternatif metode, MRP PPB memiliki biaya paling rendah dibandingkan metode lainnya. Namun dengan mempertimbangkan kelemahan teknik MRP PPB ini bila diterapkan di PLTD Klademak Sorong adalah resiko dapat berkurang akibat adanya penyusutan, kebocoran, ataupun penurunan kualitas bahan, dimana hal ini dapat terjadi karena masa penyimpanan di tangki akan lebih lama, sehingga alternatif yang dipilih sebagai metode yang digunakan dalam pengemdalian persediaan adalah MRP teknik EOQ.
\end{abstract}

Kata Kunci : Pengendalian Persediaan, Material Resource Planning, Peramalan Permintaan

\section{PENDAHULUAN}

\subsection{Latar Belakang}

Agar mampu bersaing dalam pasar industri, salah satu faktor produksi yang perlu dilakukan efisiensi adalah bahan baku yang merupakan faktor penting dalam produksi, kekurangan bahan baku yang tersedia (Out of stock) dapat berakibat terhentinya proses produksi yang sedang berlangsung sampai tersedianya kembali bahan baku. Selain itu persediaan bahan baku yang relatif kecil akan mengakibatkan frekwensi pembelian bahan baku menjadi lebih sering, sehingga biaya pemesanan bahan baku perusahaan menjadi lebih besar.

PLTD Klademak dalam peranannya sebagai salah satu pemasok energi listrik di kota Sorong dan sekitarnya, menggunakan bahan bakar minyak solar jenis High Speed Diesel sebagai bahan baku utama produksi serta bahan pelumas jenis Elf Disola untuk pelumasannya. Dalam penyediaan energi listrik, PLTD Klademak ditargetkan memproduksi $1.000 .000 \mathrm{kwh}$ per tahun. Sementara kebutuhan energi listrik kota Sorong mengalami peningkatan permintaan sebesar 20\% per tahun, sehingga membuat perusahaan menaikkan kapasitas produksi Generator dari $4000 \mathrm{kwh} / \mathrm{jam}$ menjadi $6000 \mathrm{kwh} / \mathrm{jam}$.

Tujuan yang akan dicapai pada penelitian ini adalah menentukan Metode MRP terbaik untuk diterapkan perusahaan dalam pengendalian persediaan bahan baku melalui perbandingan total biaya persediaan dari Metode MRP yang dihasilkan, dan membuat peramalan kebutuhan bahan baku periode berikutnya dengan menggunakan Metode MRP Terbaik tersebut 


\subsection{Tujuan Penelitian}

Tujuan dari penelitian ini adalah :

1. Untuk mengetahui tingkat keoptimalan pelaksanaan manajemen persediaan bahan baku pada PLTD Klademak Sorong.

2. Menentukan alternatif teknik pengendalian persediaan bahan baku dengan menggunakan metode $M R P$ yang dapat dipilih oleh PLTD Klademak Sorong.

3. Membuat ramalan permintaan (Forecasting demand) Bahan Bakar Minyak HSD untuk tahun 2017 dengan menggunakan metode pengendalian persediaan terpilih, berdasarkan hasil analisa data pengendalian persediaan pada tahun 2015 dan 2016

\section{METODOLOGI}

\subsection{Lokasi Penelitian}

Penelitian ini merupakan praktek lapangan yang mempelajari kasus yang terjadi di PLTD Klademak, Sorong, Papua Barat. Pemilihan lokasi dilakukan secara sengaja (Purpossive) dengan pertimbangan bahwa perusahaan ini cukup besar dan berpengalaman serta membutuhkan bahan baku dalam jumlah yang besar.

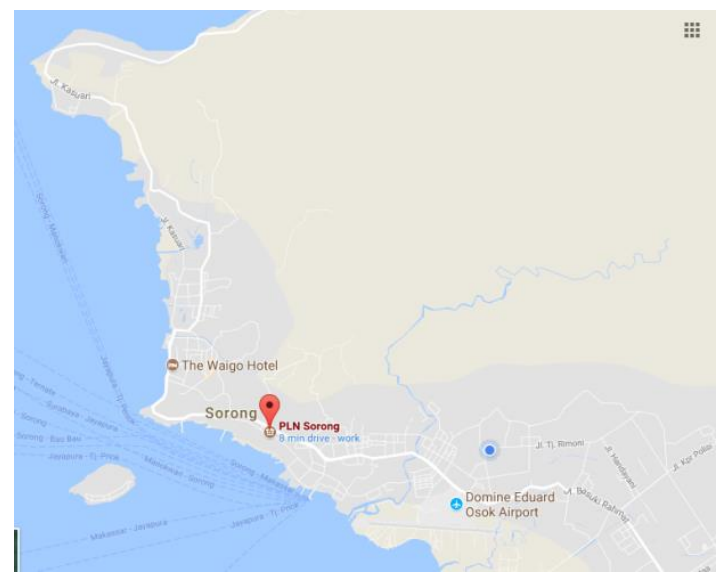

Gambar 1. Lokasi penelitian

\subsection{Teknik Pengumpulan data}

Pengumpulan data terbagi dua yaitu data primer dan data sekunder. Data primer yang diambil adalah data tentang saldo, pemesanan, penerimaan, pemakaian, biaya pemesanan, biaya penyimpanan, dan biaya perawatan Bahan Bakar Minyak HSD (High Speed Diesel) pada PLTD Klademak Sorong, selama periode tahun 2015 dan 2016. Teknik pengumpulan data menggunakan metode dokumentasi, observasi, dan wawancara. Sedangkan data sekunder diperoleh dengan mengolah data primer menjadi suatu data yang dibuthukan dalam analisa penelitian ini.

\subsection{Teknik Pengolahan dan Analisa Data}

Dari data yang diperoleh kemudian diolah menggunakan metode pendekatan MRP teknik $L F L, E O Q$, dan $P P B$. Setelah itu dibuatkan rumusan hasil analisa data yaitu perbandingan Frekwensi Pemesanan, Biaya Pemesanan, Jumlah Pemesanan, Biaya Penyimpanan, dan Biaya Persediaan yang timbul. Selain melakukan perbandingan antar model, juga dilakukan perbandingan terhadap sistem pengendalian persediaan yang selama ini dilakukan oleh perusahaan, sehingga dapat ditentukan alternatif sistem pengendalian persediaan yang tepat bagi perusahaan. Kemudian membuat ramalan permintaan untuk periode tahun 2017 dengan menggunakan metode yang terpilih.

\section{HASIL DAN PEMBAHASAN}

\subsection{Data Hasil Penelitian}

Pada penelitian ini diperoleh data fasilitas penyimpanan BBM HSD pada PLTD Klademak berupa tangki penyimpanan (Storage tank) sebanyak 4 buah dengan kapasitas penyimpanan maksimum sebesar 265.000 liter. 
Tabel 1. Kapasitas Tangki Penyimpanan BBM HSD PLTD Klademak

\begin{tabular}{ccr}
\hline Tangki & Jenis Tangki & \multicolumn{1}{c}{$\begin{array}{c}\text { Kapasitas } \\
\text { (Liter) }\end{array}$} \\
\hline 1 & Receiving tank & 100.000 \\
2 & Receiving tank & 100.000 \\
3 & Receiving tank & 60.000 \\
4 & Daily Tank & 5.000 \\
& Total & 265.000 \\
\hline & & Sumber : PLTD Klademak, 2016
\end{tabular}

\subsection{Data Biaya Persediaan}

Biaya persediaan yang dibahas dalam penelitian ini hanya biaya pemesanan dan biaya penyimpanan bahan baku, sedangkan biaya-biaya yang lainnya tidak terdapat di PLTD Klademak. Secara umum total biaya persediaan terdiri dari biaya pemesanan dan biaya penyimpanan.

\subsubsection{Biaya Pemesanan}

Biaya pemesanan menggambarkan jumlah biaya yang harus dikeluarkan untuk setiap proses pemesanan, biaya tersebut antara lain biaya ekspedisi dan administrasi, biaya pembuatan Purchase order, biaya bongkar muat.

Rincian biaya pemesanan BBM HSD yang dikeluarkan oleh PLTD Klademak Sorong terangkum dalam Tabel 2 berikut.

Tabel 2. Biaya Pemesanan per Pesanan BBM HSD Tahun 2015-2016

\begin{tabular}{|c|c|c|c|c|}
\hline Jenis Biaya & \multicolumn{2}{|c|}{ Tahun 2015} & \multicolumn{2}{|c|}{ Tahun 2016} \\
\hline Ekspedisi dan Administrasi & Rp. & $61.000,00$ & Rp. & $61.000,00$ \\
\hline $\begin{array}{l}\text { Pembuatan } \\
\text { Faktur PO }\end{array}$ & Rp. & $21.000,00$ & Rp. & $21.000,00$ \\
\hline Biaya Bongkar Muat & \multicolumn{2}{|c|}{ Rp. $4.750 .000,00$} & \multicolumn{2}{|c|}{ Rp. $7.083 .333,33$} \\
\hline Total & \multicolumn{2}{|c|}{ Rp. 4.832.000,00 } & \multicolumn{2}{|c|}{ Rp. $7.165 .333,33$} \\
\hline
\end{tabular}

\subsubsection{Biaya Penyimpanan}

Beberapa biaya yang timbul akibat aktivitas penyimpanan antara lain :

a. Biaya perawatan

Tangki penyimpanan BBM HSD sebagai salah satu aset perusahan perlu dilakukan pemeliharaan sebab berhubungan dengan aktivitas penyimpanan BBM HSD. Besarnya biaya perawatan tangki penyimpanan BBM HSD PLTD Klademak Sorong terlihat pada Tabel 3 di bawah ini.

Tabel 3. Biaya Perawatan HSD Storage Tank Tahun 2015-2016

\begin{tabular}{|c|c|c|}
\hline Tahun & \multicolumn{2}{|c|}{ Biaya Perawatan Tangki } \\
\hline 2015 & Rp. & $44.506 .000,00$ \\
\hline 2016 & Rp. & $44.506 .000,00$ \\
\hline Total & Rp. & $89.012 .000,00$ \\
\hline
\end{tabular}

b. Losses allowance cost

Data Losses allowance cost diperoleh dari bagian keuangan dan akuntansi yang menetapkan besarnya risiko biaya yang timbul akibat hilangnya bahan baku selama proses penyimpanan sebesar $0,1 \%$ dari biaya pembelian BBM HSD yang dilakukan. 
Tabel 4. Losses cost penyimpanan BBM HSD Tahun 2015-2016

\begin{tabular}{ccccc}
\hline Tahun & $\begin{array}{c}\text { Pembelian } \\
(\text { Liter })\end{array}$ & $\begin{array}{c}\text { Harga } \\
\text { (Rp./Liter) }\end{array}$ & $\begin{array}{c}\text { Biaya pembelian } \\
\text { (Rp.) }\end{array}$ & $\begin{array}{c}\text { Biaya penyusutan } \\
(0,1 \%)\end{array}$ \\
\hline 1 & 2 & 3 & $4=2 \times 3$ & $5=4 \times(0,1 \%)$ \\
2015 & 950.000 & Rp. $5.990,5$ & Rp. $5.690 .975 .000,00$ & Rp. $5.690 .975,00$ \\
2016 & 1.700 .000 & Rp. $4.566,0$ & Rp. $7.762 .200 .000,00$ & Rp. $7.762 .200,00$ \\
\hline
\end{tabular}

Sumber : Data primer yang diolah, 2016

c. Biaya asuransi

Data biaya asuransi diperoleh dari bagian keuangan dan akuntansi bahwa semua BBM HSD yang dibeli diasuransikan dan dihitung sebagai Opportunity cost dari risiko yang mungkin terjadi selama penyimpanan dan pemakaian BBM HSD. Besarnya biaya asuransi sebesar $0,7 \%$ dari biaya pembelian BBM HSD. Detail biaya asuransi penyimpanan BBM HSD PLTD Klademak Sorong dapat dilihat pada Tabel 5 di bawah ini.

Tabel 5. Biaya Asuransi Penyimpanan BBM HSD Tahun 2015-2016

\begin{tabular}{crr} 
Tahun & Biaya pembelian & $\begin{array}{c}\text { Biaya asuransi } \\
(0,7 \%)\end{array}$ \\
1 & 2 & $3=2 \times(0,7 \%)$ \\
\hline 2015 & Rp. $5.690 .975 .000,00$ & Rp. $39.836 .825,00$ \\
2016 & Rp. $7.762 .200 .000,00$ & Rp. $54.335 .400,00$ \\
\hline
\end{tabular}

Sumber : Data primer yang diolah, 2016

Seluruh biaya yang timbul terkait dengan aktivitas penyimpanan BBM HSD dari tahun 2015 sampai tahun 2016, terangkum pada Tabel 6.

Tabel 6. Rincian Biaya Penyimpanan BBM HSD Tahun 2015-2016

\begin{tabular}{lrrrr}
\hline \multicolumn{1}{c}{ Jenis Biaya } & \multicolumn{2}{c}{ Tahun 2015} & \multicolumn{2}{c}{ Tahun 2016} \\
\hline Biaya perawatan tangki & Rp. & $44.506 .000,00$ & Rp. & $44.506 .000,00$ \\
Losses allowance cost & Rp. & $5.690 .975,00$ & Rp. & $7.762 .200,00$ \\
Biaya asuransi & Rp. & $39.836 .825,00$ & Rp. & $54.335 .400,00$ \\
\multicolumn{1}{c}{ Total } & Rp. & $90.033 .800,00$ & Rp. & $106.603 .600,00$ \\
\hline
\end{tabular}

Sumber : Pengolahan data

d. Biaya Penyimpanan per Liter per Tahun $(\mathrm{H})$

1. Biaya Penyimpanan / Liter / Tahun (H) (2015)

$=1,58 \%$ x Rp. $5 \cdot 990,5$

$=$ Rp. 94,65

2. Biaya Penyimpanan / Liter / Tahun (H) (2016)

$=1,37 \%$ x Rp. 4.566

$=$ Rp. 62,55

\subsection{Data pemakaian}

Dalam proses produksi setiap shift, petugas administrasi PLTD melakukan pencatatan laporan harian operator ke dalam Logsheet journal yang telah disediakan sehingga dapat dipantau berapakah pemakaian bahan bakar minyak HSD setiap harinya. Berikut data pemakaian BBM HSD dari tahun 2015 sampai 2016. 


\section{Tabel 7. Data Pemakaian BBM HSD PLTD Klademak}

\begin{tabular}{lrr}
\hline Pemakaian (Liter) & Tahun 2015 & Tahun 2016 \\
\hline Januari & 143.933 & 145.174 \\
Februari & 146.275 & 69.600 \\
Maret & 140.760 & 117.765 \\
April & 91.715 & 86.785 \\
Mei & 36.125 & 102.600 \\
Juni & 9.103 & 64.503 \\
Juli & 20.559 & 60.549 \\
Agustus & 6.255 & 110.055 \\
September & 35.783 & 204.980 \\
Oktober & 50.732 & 282.602 \\
Nopember & 125.418 & 248.721 \\
Desember & 157.576 & 227.368 \\
Total $(\Sigma X)$ & 964.234 & 1.720 .702 \\
Rata-rata $(\bar{X})$ & 80.353 & 143.392 \\
\hline Sumber $:$ PLTD Klademak, 2016
\end{tabular}

\subsection{Analisa Data Pengendalian Persediaan BBM}

Setelah dilakukan perhitungan dengan menggunakan formulasi yang ada maka dapat dibuat analisa sebagai berikut :

\subsubsection{Frekwensi pesanan}

Tabel 8. Perbandingan Frekwensi Pemesanan Bahan Baku

\begin{tabular}{ccccc}
\hline \multirow{2}{*}{ Tahun } & $\begin{array}{c}\text { Cara } \\
\text { Perusahaan } \\
\text { (Kali) }\end{array}$ & $\begin{array}{c}\text { MRP } \\
\text { LFL } \\
\text { (Kali) }\end{array}$ & MRP & $\begin{array}{c}\text { MRP } \\
\text { (Kali) }\end{array}$ \\
\hline 2015 & 10 & 12 & 6 & 5 \\
2016 & 12 & 12 & 8 & 5 \\
Total & 22 & 24 & 14 & 10 \\
\hline
\end{tabular}

Banyaknya pemesanan yang dilakukan berkaitan langsung dengan biaya pemesanan. Semakin kecil frekwensi pemesanan akan semakin kecil pula biaya yang dikeluarkan untuk pemesanan. Tabel di atas menunjukkan bahwa frekwensi pesanan terkecil diperoleh pada Metode MRP PPB yaitu sebanyak 10 kali.

\subsubsection{Biaya pemesanan}

Tabel 9. Perbandingan Biaya Pemesanan Bahan Baku

\begin{tabular}{ccccc} 
& $\begin{array}{c}\text { Cara } \\
\text { Perusahaan } \\
\text { Tahp })\end{array}$ & $\begin{array}{c}\text { MRP } \\
\text { LFL } \\
(\mathrm{Rp})\end{array}$ & $\begin{array}{c}\text { MRP } \\
\text { EOQ } \\
(\mathrm{Rp})\end{array}$ & $\begin{array}{c}\text { MRP } \\
\text { PPB } \\
(\mathrm{Rp})\end{array}$ \\
\hline 2015 & $48.320 .000,00$ & $57.984 .000,00$ & $28.992 .000,00$ & $24.160 .000,00$ \\
2016 & $85.984 .000,00$ & $85.984 .000,00$ & $57.322 .666,67$ & $35.826 .666,67$ \\
Total & $134.304 .000,00$ & $143.968 .000,00$ & $86.314 .666,67$ & $59.986 .666,67$ \\
\hline
\end{tabular}


Total biaya pemesanan berbeda-beda pada keempat metode tersebut, hal ini disebabkan berbedanya kuantitas bahan baku yang dipesan dari pemasok. Makin besar kuantitas pemesanan, maka akan menyebabkan makin besar pula total biaya pemesanan. Dalam kasus ini, biaya pemesanan terendah terjadi pada MRP LFL.

\subsubsection{Kuantitas Pemesanan.}

Tabel 10. Perbandingan Kuantitas Pemesanan Bahan Baku

\begin{tabular}{ccccc}
\hline Tahun & $\begin{array}{c}\text { Cara } \\
\text { Perusahaan } \\
\text { (Liter) }\end{array}$ & $\begin{array}{l}\text { MRP } \\
\text { LFL } \\
\text { (Liter) }\end{array}$ & $\begin{array}{c}\text { MRP } \\
\text { EOQ } \\
\text { (Liter) }\end{array}$ & $\begin{array}{c}\text { MRP } \\
\text { PPB } \\
\text { (Liter) }\end{array}$ \\
\hline 2015 & 950.000 & 849.326 & 866.230 & 849.326 \\
2016 & 1.700 .000 & 1.620 .028 & 1.749 .881 & 1.620 .028 \\
Total & 2.650 .000 & 2.469 .354 & 2.616 .111 & 2.469 .354 \\
\hline
\end{tabular}

Sumber : Data primer yang diolah, 2016

Kuantitas yang dipesan menunjukkan kuantitas yang akan disimpan, semakin besar bahan baku yang dipesan, akan semakin besar pula biaya penyimpanan yang ditimbulkannya.

\subsubsection{Biaya Penyimpanan.}

Tabel 11. Perbandingan Biaya Penyimpanan Bahan Baku

\begin{tabular}{ccccr}
\hline Tahun & $\begin{array}{c}\text { Cara } \\
\text { Perusahaan } \\
(\mathrm{Rp})\end{array}$ & $\begin{array}{l}\text { MRP } \\
\text { LFL } \\
(\mathrm{Rp})\end{array}$ & \multicolumn{1}{c}{$\begin{array}{l}\text { MRP } \\
\text { EOQ } \\
(\mathrm{Rp})\end{array}$} & \begin{tabular}{c}
\multicolumn{1}{c}{$\begin{array}{c}\text { MRP } \\
\text { PPB }\end{array}$} \\
$(\mathrm{Rp})$
\end{tabular} \\
\hline 2015 & $9.233 .626,21$ & $453.167,95$ & $7.819 .304,30$ & $5.253 .053,68$ \\
2016 & $5.883 .274,64$ & $262.399,23$ & $8.148 .854,83$ & $7.067 .628,95$ \\
Total & $15.116 .900,85$ & $715.567,18$ & $15.968 .159,14$ & $12.320 .682,62$ \\
\hline
\end{tabular}

Sumber : Data primer yang diolah, 2016

Total biaya persediaan bahan baku dengan menggunakan MRP LFL paling rendah dibandingkan teknik yang lainnya. Walaupun MRP LFL menyebabkan biaya pemesanan lebih tinggi dari teknik yang lain, tetapi teknik ini menghasilkan biaya penyimpanan paling rendah yang mengakibatkan total biaya persediaan menjadi lebih rendah.

\subsubsection{Biaya Persediaan}

Tabel 12. Perbandingan Biaya Persediaan Bahan Baku

\begin{tabular}{ccccc}
\hline & $\begin{array}{c}\text { Cara } \\
\text { Terusahaan } \\
(\mathrm{Rp})\end{array}$ & $\begin{array}{l}\text { MRP } \\
\text { LFL } \\
(\mathrm{Rp})\end{array}$ & $\begin{array}{l}\text { MRP } \\
\text { EOQ } \\
(\mathrm{Rp})\end{array}$ & $\begin{array}{c}\text { MRP } \\
\text { PPB } \\
(\mathrm{Rp})\end{array}$ \\
\hline 2015 & $57.553 .626,21$ & $58.437 .167,95$ & $36.811 .304,30$ & $29.413 .053,68$ \\
2016 & $91.867 .274,64$ & $86.246 .399,23$ & $65.471 .521,50$ & $42.894 .295,61$ \\
Total & $149.420 .900,85$ & $144.683 .567,18$ & $102.282 .825,80$ & $72.307 .349,29$ \\
\hline
\end{tabular}

Sumber : Data primer yang diolah, 2016

\subsection{Analisa Data Penghematan Persediaan BBM}

Perincian penghematan biaya persediaan bahan baku PLTD Klademak Sorong terdapat pada Tabel 13. 
Tabel 13. Penghematan Total Biaya Persediaan Bahan Baku tahun 2015 - 2016

\begin{tabular}{|c|c|c|c|c|}
\hline URAIAN & $\begin{array}{c}\text { Cara } \\
\text { Perusahaan }\end{array}$ & $\begin{array}{l}\text { MRP } \\
\text { LFL }\end{array}$ & $\begin{array}{l}\text { MRP } \\
\text { EOQ }\end{array}$ & $\begin{array}{l}\text { MRP } \\
\text { PPB }\end{array}$ \\
\hline Total Biaya Persediaan (Rp) & $149.420 .900,85$ & $144.683 .567,18$ & $102.282 .825,80$ & $72.307 .349,29$ \\
\hline $\begin{array}{l}\text { Penghematan thdp Cara } \\
\text { Perusahaan (Rp) }\end{array}$ & - & 4.737.333,67 & 47.138.075,04 & $77.113 .551,56$ \\
\hline Persentase Penghematan (\%) & - & 3,2 & 31,5 & 51,6 \\
\hline
\end{tabular}

Sumber : Data primer yang diolah, 2016

Dari segi penghematan biaya, diketahui bahwa teknik MRP PPB yang memiliki nilai tertinggi yaitu sebesar 51,6\%. Namun dengan adanya pertimbangan dari sudut pandang lain yang telah dijelaskan sebelumnya, sehingga teknik MRP PPB tidak dapat diterapkan. Untuk itu, maka alternatif teknik yang paling cocok diterapkan untuk pengendalian persediaan bahan baku di PLTD Klademak Sorong adalah metode MRP EOQ yang memiliki nilai tertinggi kedua setelah metode MRP PPB, dengan penghematan sebesar 31,5\% dari metode yang dilakukan perusahaan.

Peramalan Permintaan BBM HSD 2017 dengan menggunakan metode Exponential Smoothing

Hasil peramalan dengan menggunakan metode Exponential Smoothing dapat dilihat pada tabel berikut.

Tabel 14. Peramalan Permintaan BBM HSD 2017 dengan menggunakan metode

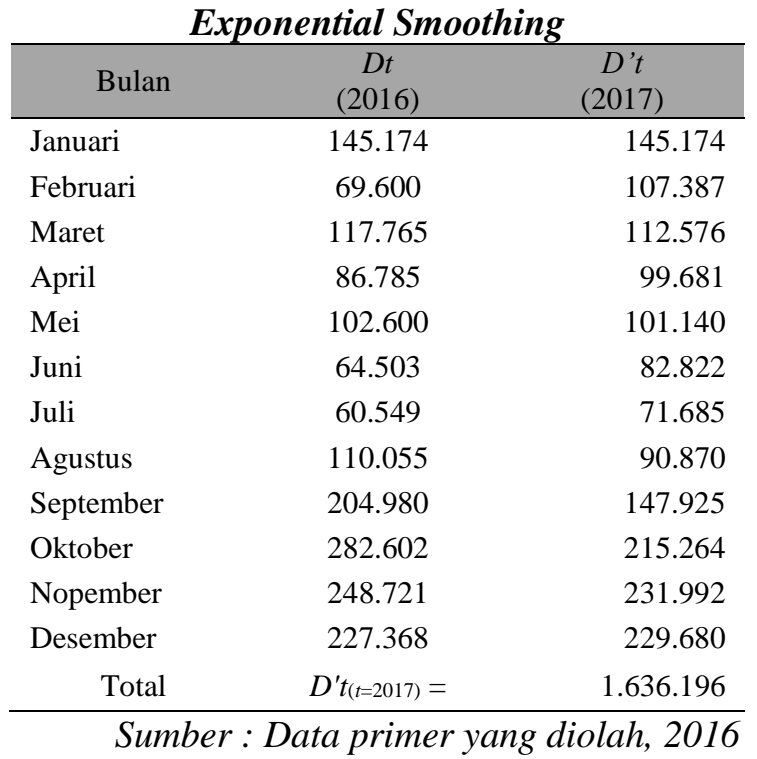

Dari Tabel 14 diketahui besarnya peramalan permintaan BBM HSD pada tahun $2017\left(D^{\prime} t\right)$ sebesar 1.636.196 liter.

\section{Pengendalian Persediaan BBM HSD Metode EOQ untuk Ramalan Tahun 2017}

Untuk menerapkan sistem pengendalian persediaan BBM HSD di PLTD Klademak Sorong dengan metode EOQ di tahun 2017 tentu membutuhkan data tentang peramalan permintaan pemakaian $D^{\prime} t_{(t=2017)}$, dimana dari hasil perhitungan peramalan diperoleh perkiraan besarnya pemintaan BBM HSD di tahun 2017 sebanyak 1.636.196 liter dengan harga per liter BBM HSD sebesar Rp. 5.278,25 per liter.

Selain itu juga dibutuhkan data tentang biaya pemesanan (S) BBM HSD di tahun yang akan datang, serta membutuhkan juga data biaya penyimpanan $(h)$. Dapat diasumsikan bahwa biaya yang akan muncul sebanding dengan biaya tahun sebelumnya berdasarkan rata-rata jumlah pembelian BBM HSD di tahun sebelumnya.

Sehingga diperoleh sebagai berikut :

- Biaya Pemesanan per Pesanan (S) BBM HSD Tahn 2017 = Rp. 9.713.946

- Biaya Penyimpanan (h) BBM HSD Tahun 2017 : 124.048.909,79

- Biaya Penyimpanan / Liter / Tahun $(\mathrm{H})(2017)=$ Rp. 75,82 


\section{KESIMPULAN}

Dari Berdasarkan hasil penelitian yang telah dilaksanakan penulis dapat menyimpulkan bahwa :

1. Dari hasil perbandingan antar metode perusahaan dengan metode MRP maka dapat diketahui bahwa cara pengendalian persediaan bahan baku yang dilakukan perusahaan selama tahun 2015-2016 belum mampu mengoptimalkan persediaan material bahan baku perusahaan.

2. Dibandingkan dengan metode perusahaan selama tahun 2015-2016, maka persentase penghematan biaya persediaan yang dihasilkan melalui penerapan MRP adalah sebesar 3,2 \% pada teknik $L F L$, dan $31,5 \%$ pada teknik $E O Q$, serta $51,6 \%$ pada teknik $P P B$.

Dimana dari ketiga alternatif metode tersebut, ternyata MRP PPB memiliki biaya paling rendah dibandingkan metode lainnya. Namun kelemahan teknik MRP PPB ini bila diterapkan di PLTD Klademak Sorong adalah resiko dapat berkurang akibat adanya penyusutan, kebocoran, ataupun penurunan kualitas bahan, dimana hal ini dapat terjadi karena masa penyimpanan di tangki akan lebih lama, sehingga alternatif yang dipilih adalah MRP teknik EOQ.

3. Dengan menggunakan metode peramalan terpilih dengan nilai MAPE terkecil yaitu Exponential Smoothing, maka diperoleh peramalan kebutuhan pemakaian BBM HSD PLTD Klademak Sorong tahun 2017 adalah sebesar 1.636 .196 liter.

Kemudian dengan menggunakan metode terpilih yaitu metode EOQ, diperoleh frekwensi pemesanan dalam setahun sebanyak 3 kali dengan kuantitas jumlah setiap kali pemesanan adalah sebesar 650.000 liter (130 truk tangki @ 5.000 liter). Titik pemesanan kembali ketika level persediaan sudah mencapai 65.829 liter, dengan Safety stock yang diijinkan adalah sebesar 3.071 liter.

\section{DAFTAR PUSTAKA}

Assauri, S. (2016). Manajemen Operasi Poduksi (Edisi 3). Jakarta: PT RajaGrafindo Persada.

Ginting, R. (2007). Sistem Poduksi (Edisi 1). Yogyakarta: Graha Ilmu.

Priyana, E.D. (2011, December). Mau Tahu Lebih Jauh Tentang Peramalan???. Retrieved October 19, 2016, from http://eftadhartikasari.blogspot.co.id/ 2011/12/peramalan-peramalan-adalahkegiatan.html

Rosid, I.A. (2014, Oct). Menghitung Kesalahan Peramalan Dengan Menggunakan MAPE (Mean Square Percent Error). Retrieved February 25, 2017, from http://ieinu.blogspot.co.id/2014/10/menghitung-kesalahan-peramalan-dengan_51.html

Saputra, A.H. (2010, Dec). Apa Itu MAPE, MAD, dan MSD? Pada Analisis Forecast... Retrieved February 25, 2017, from http://arsyil.blogspot. co.id/2010/12/apa-itu-mape-mad-dan-msdpada-analisis.html?m=1

Satria, A. (2016, May). Metode Pengendalian Persediaan Dengan Jumlah Pemesanan Ekonomis atau Economic Order Quantity (EOQ). Retrieved October 19, 2016, from http://www.materibelajar.id/2016/05/metode-pengendalian-persediaan-dengan.html

Suyantoro, S. (2014). Mengolah Data Statistik Hasil Penelitian Menggunakan SPSS. Semarang: Wahana Komputer \& Yogyakarta: Andi Offset

Taryana, N. (2008). Analisis Pengendalian Persediaan Bahan Baku Pada Produk Sepatu Dengan Pendekatan Teknik Lot Sizing Dalam Mendukung Sistem MRP. (Skripsi). Fakultas Teknologi Pertanian, Institut Pertanian Bogor, Bogor.

Tim Penyusun. (2014). Pedoman Penulian Tugas Akhir Bagi Mahasiswa Fakultas Teknik. Fakultas Teknik, Universitas Muhammadiyah Sorong, Sorong.

Wibowo, I. (2010). Analisis Peramalan Penjualan Rokok Golden Pada PT. Djitoe Indonesian Tobacco Coy Surakarta. (Tugas Akhir). Fakultas Ekonomi, Jurusan Manajemen Industri, Universitas Sebelas Maret, Surakarta.

Wisono, Y.C. (2011). Analisa Sistem Pengendalian Bahan Bakar Minyak High Speed Diesel Dengan Metode Economic Order Quantity (EOQ) Pada PT. Frisian Flag Plant Pasar Rebo. (Skripsi). Fakultas Teknik, Program Studi Teknik Industri, Universitas Indonesia, Depok. 